\title{
Influence of white mineral trioxide aggregate on inflammatory cells before and after expiry date
}

\begin{abstract}
Mohammad Ali Saghiri ${ }^{1}$, Mehrdad Lotfi $^{2}$, Noushin Shokouhinejad ${ }^{3,4}$, Kamal Asgar ${ }^{5}$, Payman Mehrvarzfar $^{6}$

${ }^{1}$ Department of Dental Material, Azad University, Dental Branch, Tehran; ${ }^{2}$ Research Center for Pharmaceutical Nanotechnology and Department of Endodontics, Dental Faculty, Tabriz University (Medical Sciences), Tabriz; ${ }^{3}$ Department of Endodontics, School of Dentistry/Dental Research Center, Tehran University of Medical Sciences; ${ }^{4}$ Iranian Center for Endodontic Research, Tehran, Iran; ${ }^{5}$ Department of Dental and Biological Materials, University of Michigan, Ann Arbor, MI, USA; ${ }^{6}$ Department of Endodontics, Dental Branch, Islamic Azad University, Tehran, Iran
\end{abstract}

Correspondence to: Mohammad Ali Saghiri, Assistant Professor, Department of Dental Material, Dental Branch, Islamic Azad University, PO Box 14665-1445, Tehran, Iran

Tel.: +982144420250

Fax: +982144475524

e-mail: saghiri@gmail.com

Accepted 9 September, 2011

\begin{abstract}
Introduction: The aim of this study was to compare the effect of subcutaneously implanted white mineral trioxide aggregate (WMTA) on inflammatory reactions before and after expiry date. Methods: Fifty Wistar rats were used in this study. Polyethylene tubes were filled with WMTA with expiry dates of 2008, 2009, and 2011, and empty ones serving as the controls were implanted into the subcutaneous tissue. The rats were sacrificed at 7-, 14-, 28-, and 60-day intervals. 5- $\mu \mathrm{m}$ sections were stained with hematoxylin and eosin and observed under a light microscope. Inflammatory reactions were categorized as 0 , none (without inflammatory cells); 1 , mild (inflammatory cells $<25$ ); 2 , moderate (25-125 inflammatory cells); and 3, severe (more than 125 inflammatory cells). Statistical analysis was performed with Kruskal-Wallis test. Results: All the experimental materials provoked moderate to severe inflammatory reactions after 7 days, which significantly differed from the control group $(P<0.05)$. At 14-day interval, WMTA with expiry date of 2008 and the control group elicited mild to moderate infiltration of inflammatory cells. However, WMTA with expiry dates of 2009 and 2011 provoked moderate to severe inflammatory reactions, which were significantly different from WMTA with expiry date of 2008 and the control group $(P<0.05)$. At 28- and 60-day intervals, the overall inflammation subsided in all the groups to mild to moderate infiltration of inflammatory cells without any significant differences $(P<0.05)$. Conclusion: It seems that the expiry date has less negative effects on the response of inflammatory cells. WMTA keeps its biocompatibility even after expiry date.
\end{abstract}

Mineral trioxide aggregate (MTA) was developed as a root-end filling material at Loma Linda University in 1993 (1). The principal components of this material are tricalcium silicate, tricalcium aluminate, tricalcium oxide, and silicate oxide (2). MTA is currently marketed in two forms: gray (GMTA) and white (WMTA). Investigations have shown that contrary to WMTA, the gray one contains lower amounts of iron, aluminum, and magnesium, leading to discoloration potential of GMTA (3). MTA has been used for pulp capping, pulpotomy, repair of root perforations, apical barrier formation in non-vital teeth with open apices, and root canal filling (4).

Although MTA has many indications in endodontics, its usage is not as widespread as that of materials such as composite resins, gutta-percha or root canal sealers, luting agents, etc. in a general practitioner dental office. It has been reported that the shelf life of almost half of dental cements and base/liner materials may be past the manufacturer's expiry date at the time of clinical use (5). The period that dental materials are stored before use and the conditions under which they are stored and shipped to the user may have detrimental effects on their physical, mechanical, and chemical properties, and ultimately on their clinical efficacy (6).

Some of the effects of aging on different dental materials, such as gutta-percha (7), composite resins (8), dental luting agents (9), and root canal sealers (10), have been investigated. The influence of environmental conditions on mechanical and physical properties of WMTA has been investigated in some research studies, including the evaluation of sealing ability at different $\mathrm{pH}$ values (11), setting time $(12,13)$, surface hardness $(14,15)$, and the morphology of WMTA stored under various conditions (16). In addition, the effect of different storage temperatures on microhardness, surface topography, and phase structure of WMTA has been previously evaluated (17). However, there is no available data on the physical and chemical properties of expired MTA.

Several in vitro and in vivo tests are used to evaluate the biocompatibility of dental materials, such as testing the cytotoxicity of materials in a cell culture, implantation tests, and animal studies (4). The results of a meta analysis showed that MTA is more biocompatible than IRM, Super EBA, and silver amalgam (18). 
A number of studies have investigated subcutaneous responses to various types of MTA (19-23). There have been some conflicting results regarding subcutaneous reactions to white MTA (WMTA) and gray MTA (GMTA; 19, 20). It has been reported that WMTA is more biocompatible than GMTA after 3 days, but GMTA is more biocompatible than WMTA after 7 days, with no significant differences in their biocompatibility after 21 days (19). A study found no differences between the inflammatory responses to GMTA and WMTA (20). In a study, $2.5 \mathrm{wt} \% \mathrm{Na}_{2} \mathrm{HPO}_{4}$ was added to WMTA and a significantly lower inflammatory response was reported compared with WMTA when the materials were implanted subcutaneously (22). To date, there are no available data regarding the biocompatibility of expired MTA. Therefore, the aim of this study was to evaluate the effect of subcutaneously implanted WMTA on inflammatory reactions before and after expiry date.

\section{Materials and methods}

The research protocol was approved by the Research Ethics Committee of Kamal Asgar Research Center (protocol no. KARC/10B2010-45-11). This study was similar to those carried out previously $(20,22)$. Fifty $2-3-$ month-old male Wistar albino rats weighting $250 \pm 30 \mathrm{~g}$ were used in this study. All the ethical and human criteria contained in Helsinki declaration and all the recommended points by Institutional Animal Care and Use Committee in the care and use of laboratory animals were observed in the different stages of the project. The following materials were examined: ProRoot white MTA sachets (Tooth-colored Formula; Dentsply Tulsa Dental, Johnson City, TN, USA) were selected and divided into three groups of 10 each as shown in Table 1. Each sachet was mixed with its ampoule according to manufacturer's instructions under aseptic conditions.

The animals were anesthetized with diethyl ether using the chamber induction method. Three separate $2-\mathrm{cm}$ incisions were made on the back of the rats at least $2 \mathrm{~cm}$ away from each other. Freshly mixed materials were prepared according to the recommendations of the manufacturer. In expired ampoules, sterile distilled water for injection was used to avoid the use of un-sterile distilled water and compensate for lack of water to meet powder/liquid ratio of $3: 1$ by weight. All the samples were placed in sterile polyethylene tubes with a $1.1-\mathrm{mm}$ inner diameter and 8-mm length and were immediately implanted subcutaneously in two separate incisions. An empty polyethylene tube was implanted in the third incision in each animal as a control at 7-, 15-, 30-, and 60 -day intervals. The rats were euthanized by administrating a high dose of diethyl ether in an induction chamber.

Table 1. Groups of MTA used in this study

\begin{tabular}{lll}
\hline Group & Lot number & Expiry date \\
\hline I & 083006 & $01 / 2011$ \\
II & 06002895 & $07 / 2009$ \\
III & 05004913 & $12 / 2008$ \\
\hline
\end{tabular}

The tubes and surrounding tissues were removed in block and fixed in $10 \%$ buffered formalin solution for 2 weeks. $5-\mu \mathrm{m}$ tissue sections were prepared longitudinally through the midline of the tubes and stained with hematoxylin and eosin. Quantitative evaluations of inflammatory cells (lymphocytes, plasmocytes, polymorphonuclear leukocytes, macrophages, and giant cells) were made in microscopic fields adjacent to the test materials at the end of the tubes under a light microscope (Carl Zeiss, Oberkochen, Germany) at ×500 magnification. An average value for each specimen was obtained from the sum of cells counted in four separate areas (2426). The observer did not have any knowledge of the materials used in specimens. The overall mean value for each material was determined in subjects at each period.

The inflammatory reactions were categorized as:

0 : none (without inflammatory cells);

1: mild ( $<25$ inflammatory cells);

2: moderate (25-125 inflammatory cells);

3: severe (more than 125 inflammatory cells).KruskalWallis and Mann-Whitney tests were used for statistical analyses. Statistical significance was defined at $P<0.05$.

\section{Results}

At 7-day interval, the mean inflammation grades were $2.6 \pm 0.51,2.4 \pm 0.51$, and $2.8 \pm 0.42$ for WMTA that expired in 2008, 2009, and 2011, respectively, consisting of moderate to severe infiltration of inflammatory cells (Fig. 1). There were no significant differences among the groups $(P=0.2)$. At 14 -day interval, the mean inflammation grades were $1.8 \pm 0.42,2.3 \pm 0.48$, and $2.5 \pm 0.52$ for WMTA that expired in 2008, 2009, and 2011, respectively. MTA expiring in 2008 elicited mild to moderate infiltration of inflammatory cells (Fig. 1). MTA groups with expiry dates of 2009 and 2011 provoked moderate to severe infiltration of inflammatory cells.

There were no significant differences between WMTA with expiry dates of 2009 and $2011(P=0.374)$, but WMTA with expiry date of 2009 and 2011 showed significant differences from WMTA with expiry date of 2008 and the control group $(P<0.05)$ (Fig. 2). At 28- and 60-day intervals, the overall inflammation subsided in all the groups to mild to moderate infiltration of inflammatory cells with no significant differences $(P>0.05)$ (Fig. 2).

\section{Discussion}

In this study, the 2008 group was selected to simulate long-expired situation, 2009 was selected for short aging, and the 2011 (before expiry) was selected as gold standard. The executive part of this study was carried out in spring 2010.

In this study, subcutaneous implantation was used to evaluate the biocompatibility of materials. This method was introduced in 1966 (24) and approved in 1981 (27).

In the current study, at the 7-day interval, all the experimental groups evoked moderate to severe inflammatory reactions, which is partially consistent with the findings of a research study (20), reporting that the subcutaneous reaction to both types of MTA (WMTA 

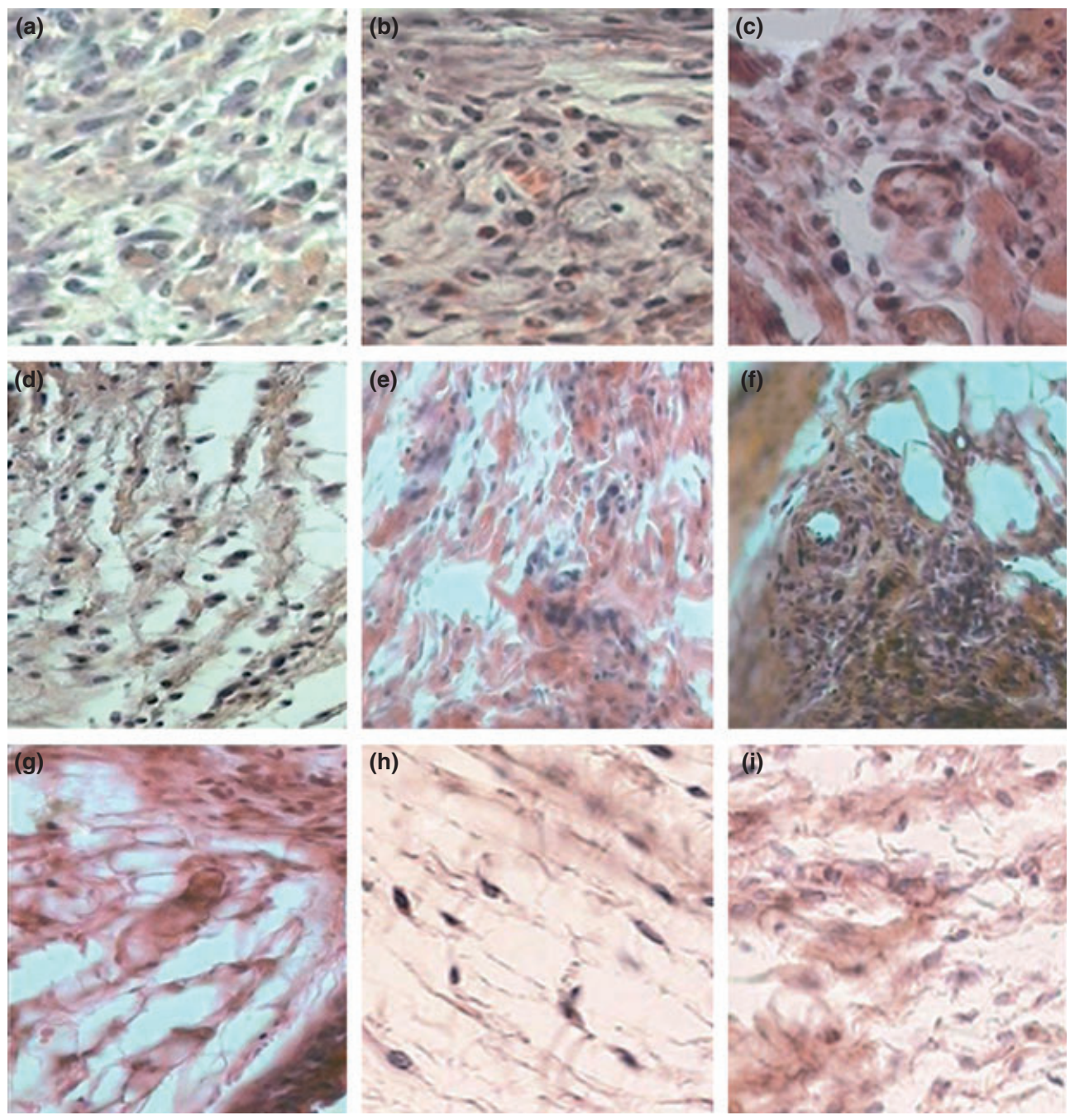

Fig. 1. Histologic images of inflammatory cell infiltration at the end of implanted tubes in the experimental groups (hematoxylineosin staining; original magnification, ×400). (a, b, c) Seven-day WMTA with expiry dates of 2008, 2009, and 2011, respectively; moderate infiltration (25-125) of inflammatory cells (lymphocytes, plasmocytes, polymorphonuclear leukocytes, and macrophages), grade 2. (d, e, f) Fourteen-day WMTA with expiry dates of 2008, 2009, and 2011, respectively; mild to moderate infiltration of lymphocytes, plasmocytes, and polymorphonuclear leukocytes is seen in WMTA with expiry dates of 2008. However, moderate to severe infiltration of lymphocytes, plasmocytes, and polymorphonuclear leukocytes is seen in WMTA with expiry dates of 2009 and 2011. (g, h, i) Twenty-eight-day WMTA with expiry dates of 2008, 2009, and 2011, respectively; mild to moderate infiltration of inflammatory cells (lymphocytes, plasmocytes, polymorphonuclear leukocytes, and macrophages) is seen in WMTA with expiry dates of 2008, 2009, and 2011.

and GMTA) was a moderate, not severe, infiltration of inflammatory cells at the 7-day interval. Another study demonstrated mild to moderated inflammatory reactions after subcutaneous implantation of WMTA after 7 days (22). In this study, the difference between experimental and control groups at 7-day interval was significant, which is consistent with the results of several studies $(20,22)$.

In this study, at 14-day interval, WMTA with expiry dates of 2011 (un-expired WMTA) and 2009 provoked moderate to severe inflammatory responses. Accordingly, the results of some studies $(20,22)$ have shown moderate to severe reactions to un-expired implanted WMTA. In our study, WMTA expired in 2008 significantly provoked fewer inflammatory reactions compared with WMTA with expiry dates of 2009 and 2011 at 14-day interval.
This study showed that at 28- and 60-day intervals, all the study groups (experimental and control) induced mild to moderate infiltration of inflammatory cells. Similarly, an investigation (20) reported mild to moderate inflammatory reactions to 30- and 60-day subcutaneously implanted WMTA and GMTA samples. When MTA powder is mixed with water, calcium phosphate and calcium oxide are released from MTA, which produce calcium hydroxide in contact with tissue fluids (28). Formation of calcium hydroxide is the cause of high alkalinity of MTA after hydration (29), which is considered an initial tissue irritant when MTA comes into contact with tissues (30). This would explain inflammatory reactions subsequent to subcutaneous implantation of MTA (31). 


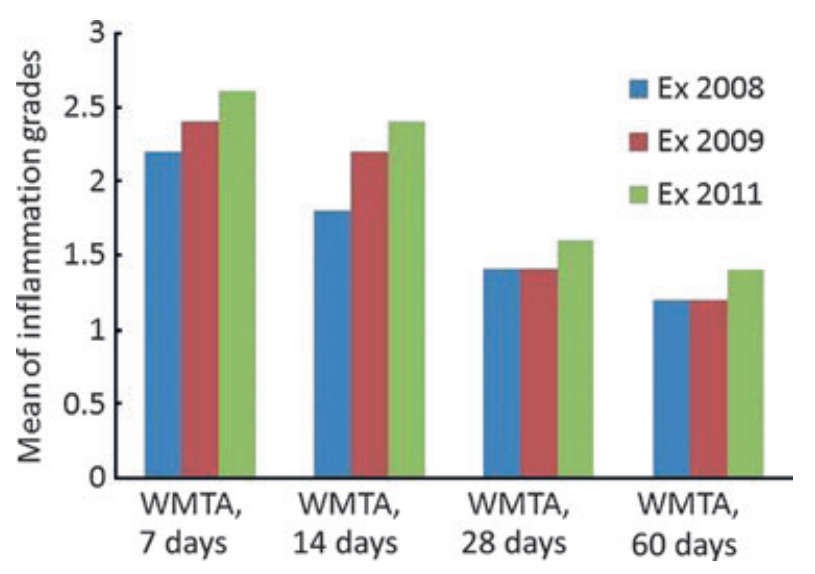

Fig. 2. The mean inflammation grades in white mineral trioxide aggregate with different expiry dates and test periods.

In conclusion, although the physical properties of WMTA may change over time, it seems that the expiry date has less negative effects on the inflammatory cells response. WMTA keeps its biocompatibility even after expiry date. Further in vitro and in vivo experiments are necessary to provide direct evidence for manufacturerdetermined expiry date for WMTA.

\section{Conflict of interest}

The authors deny any conflicts of interest related to this study.

\section{References}

1. Torabinejad M, Chivian N. Clinical applications of mineral trioxide aggregate. J Endod 1999;25:197-205.

2. Camilleri J, Pitt Ford TR. Mineral trioxide aggregate: a review of the constituents and biological properties of the material. Int Endod J 2006;39:747-54.

3. Roberts HW, Toth JM, Berzins DW, Charlton DG. Mineral trioxide aggregate material use in endodontic treatment: a review of the literature. Dent Mater 2008;24:149-64.

4. Parirokh M, Torabinejad M. Mineral trioxide aggregate: a comprehensive literature review-part III: clinical applications, drawbacks, and mechanism of action. J Endod 2010;36:400-13.

5. Hondrum SO. The US Army Institute of Dental Research dental materials shelf-life survey: lot request results. Milit Med 1991;156:491-3.

6. Johnson GH, Herbert AH, Powers JM. Changes in properties of glass-ionomer luting cements with time. Oper Dent 1988;13: 191-6.

7. Katz A, Tagger M, Tamse A. Rejuvenation of brittle guttapercha cones - a universal technique? J Endod 1987;13:65-8.

8. Tirapelli C, PanzeriI FC, PanzeriI H, PardiniII LC, Zaniquelli O. Radiopacity and microhardness changes and effect of X-ray operating voltage in resin-based materials before and after the expiration date. Mat Res 2004;7:409-12.

9. Hondrum SO. Storage stability of dental luting agents. J Prosthet Dent 1999;81:464-8.

10. Mendonça SC, de Carvalho Júnior JR, Guerisoli DM, Pécora $\mathrm{JD}$, de Sousa-Neto MD. In vitro study of the effect of aged eugenol on the flow, setting time and adhesion of Grossman root canal sealer. Braz Dent J 2000;11:71-8.

11. Saghiri MA, Lotfi M, Saghiri AM, Vosoughhosseini S, Fatemi A, Shiezadeh V et al. Effect of $\mathrm{pH}$ on sealing ability of white mineral trioxide aggregate as a root-end filling material. J Endod 2008;34:1226-9.

12. Kogan P, He J, Glickman G, Watanabe I. The effects of various additives on setting properties of MTA. J Endod 2006;32:56972.

13. Huang T, Shie M, Kao C, Ding S. The effect of setting accelerator on properties of mineral trioxide aggregate. J Endod 2008;34:590-3.

14. Namazikhah MS, Nekoofar MH, Sheykhrezae MS, Salariyeh $\mathrm{S}$, Hayes SJ, Bryant ST et al. The effect of $\mathrm{pH}$ on surface hardness and microstructure of mineral trioxide aggregate. Int Endod J 2008;41:108-16.

15. Saghiri M, Lotfi M, Saghiri A, Vosoughhosseini S, Aeinehchi M, Ranjkesh B. Scanning electron micrograph and surface hardness of mineral trioxide aggregate in the presence of alkaline pH. J Endod 2009;35:706-10.

16. Camilleri J, Montesin F, Brady K, Sweeney R, Curtis R, Ford $\mathrm{T}$. The constitution of mineral trioxide aggregate. Dent Mater 2005;21:297-303.

17. Saghiri MA, Lotfi M, Joupari MD, Aeinehchi M, Saghiri AM. Effects of storage temperature on surface hardness, microstructure, and phase formation of white mineral trioxide aggregate. J Endod 2010;36:1414-8.

18. Fernández-Yáñez Sánchez A, Leco-Berrocal MI, MartínezGonzález JM. Metaanalysis of filler materials in periapical surgery. Med Oral Patol Oral Cir Bucal 2008;1:13.

19. Shahi S, Rahimi S, Lotfi M, Yavari H, Gaderian A. A comparative study of the biocompatibility of three root-end filling materials in rat connective tissue. J Endod 2006;32:77680.

20. Vosoughhosseini S, Lotfi M, Shahi S, Baloo H, Mesgariabbasi $\mathrm{M}$, Saghiri MA et al. Influence of white versus gray mineral trioxide aggregate on inflammatory cells. J Endod 2008;34:7157.

21. Gomes-Filho JE, Watanabe S, Bernabe' PF, de Moraes Costa MT. A mineral trioxide aggregate sealer stimulated mineralization. J Endod 2009;35:256-60.

22. Lotfi M, Vosoughhosseini S, Saghiri MA, Mesgariabbasi M, Ranjkesh B. Effect of white mineral trioxide aggregate mixed with disodium hydrogen phosphate on inflammatory cells. J Endod 2009;35:703-5.

23. Parirokh MMB, Raoof M, Tabrizchi H, Haghdoost A. Comparative study of subcutaneous tissue responses to a novel root-end filling material and white and grey mineral trioxide aggregate. Int Endod J 2011;44:283-9.

24. Torneck CD. The reaction of rat connective tissue to polyethylene tube implants. Oral Surg 1966;21:379-87.

25. Zmener O, Guglielmotti MB, Cabrini RL. Biocompatibility of two calcium hydroxide-based endodontic sealers: a quantitative study in the subcutaneous connective tissue of the rat. J Endod 1988;14:229-35.

26. Zmener O, Guglielmotti MB, Cabrini RL. Tissue response to an experimental calcium hydroxide- based endodontic sealer: a quantitative study in the subcutaneous connective tissue of the rat. Endod Dent Traumatol 1990;6:66-72.

27. Olsson B, Slikowski A, Langland K. Subcutaneous implantation for the biological evaluation of endodontic materials. J Endod 1981;7:355-69.

28. Koh ET, Mc Donald F, Pitt Ford TR, Torabinejad M. Cellular response to mineral trioxide aggregate. J Endod 1998;24:543-7.

29. Camilleri J. Characterization of hydration products of mineral trioxide aggregate. Int Endod J 2008;41:408-17.

30. Yaltrik M, Ozbas H, Biligic B, Issever H. Reactions of connective tissue to mineral trioxide aggregate and amalgam. J Endod 2004;30:95-9.

31. Islam I, Chng HK, Yap AU. Comparison of the physical and mechanical properties of MTA and Portland cement. J Endod 2006;32:193-7. 